\title{
Heat transfer in premixed spark ignition engines part I: Identification of the factors influencing heat transfer
}

\author{
Stijn Broekaert ${ }^{\mathrm{a}}$, Joachim Demuynck ${ }^{\mathrm{a}}$, Thomas De Cuyper ${ }^{\mathrm{a}}$, Michel De \\ Paepe $^{\text {a }}$, Sebastian Verhelst ${ }^{\mathrm{a}}$ \\ ${ }^{a}$ Ghent University, Belgium
}

\begin{abstract}
The heat transfer from the combustion gases to the cylinder walls inside a spark ignition engine is a key factor in an engine's design, due to its influence on the engine's efficiency, power and emissions. Therefore a lot of research has been conducted in order to accurately model the heat transfer, for engine design and optimization purposes. These models have been found to provide inaccurate predictions for fuels which have significantly different gas properties compared to traditional fossil fuels. This indicates that the models either do not properly include gas properties, or are missing some important properties in their formulation. In order to construct a general ("fuel-independent") heat transfer model, new measurements need to be executed, with multiple fuels that have different properties. Designing such an experiment requires a thorough understanding of the factors influencing the heat transfer and their interactions. In this paper a literature review is presented of heat transfer measurements in spark ignition engines in order to investigate the effect of the engine factors on the heat transfer. Based on this review, a root cause analysis is conducted to identify the independent factors that affect heat transfer. These factors are then used to set up two experiments according to a Design of Experiments methodology that allows the investigation of the effect of different gas properties and engine settings on the heat transfer in a consistent way. The results of these measurements for motored operation are discussed in [1] and for fired operation in a companion paper [2].
\end{abstract}

Keywords: Heat transfer, internal combustion engine, review, experimental

\section{Introduction}

Research on in-cylinder heat transfer in spark ignition (SI) engines, has been conducted since the 1950s $[3$ in order to optimize engine design. This is because of the significant impact of the heat transfer on the engine's efficiency, power

\footnotetext{
*Stijn Broekaert

Email address: stijn.broekaert@ugent.be (Stijn Broekaert)
} 
5 and emissions [4, 5. Nowadays, simulation tools that predict the engine cycle are used in the development of new engines. The accuracy of the simulation results depends on the accuracy of the underlying models [6]. The heat transfer model plays an important role, because the heat transfer from the combustion gases to the cylinder walls needs to be calculated at every time step to solve the 10 equations of mass and energy, which are the building blocks of the simulation tools.

Models described in literature predict the convective heat transfer from the combustion gases to the cylinder walls. Because the radiative heat transfer accounts for only $5 \%$ of the total heat flux in an SI engine, it is usually neglected

15 7]. The convective heat transfer is a transient process, but can be assumed to be quasi-steady. This allows the definition of a convection coefficient (h) according to Eq. 1. because the instantaneous heat flux (q) is considered to be proportional to the temperature difference between the combustion gases $\left(T_{\text {gas }}\right)$ and the cylinder wall $\left(T_{\text {wall }}\right)$.

$$
h=\frac{q}{T_{\text {gas }}-T_{\text {wall }}}
$$

20

The underlying assumption of all the quasi-steady heat transfer models in literature is the Reynolds analogy [8, which describes the analogous behaviour of heat and momentum transfer. Reynolds derived this relation out of the boundary layer equations for laminar forced flow over a solid surface, assuming the Prandtl number to be equal to 1 and neglecting form drag. Polhausen 8 25 extended this equation for cases where the Prandtl number differs from unity (Eq. 2):

$$
N u=0.332 \cdot R e^{1 / 2} \cdot \operatorname{Pr}^{1 / 3}
$$

The Nusselt, Reynolds and Prandtl number are defined as:

$$
\begin{gathered}
N u=\frac{h \cdot L}{k} \\
R e=\frac{\rho \cdot V \cdot L}{\mu} \\
\operatorname{Pr}=\frac{\mu \cdot c_{p}}{k}
\end{gathered}
$$

In which $\mathrm{L}$ is the characteristic length, $\mathrm{k}$ the thermal conductivity, $\rho$ the density, $\mathrm{V}$ the characteristic velocity, $\mu$ the dynamic viscosity and $c_{p}$ the specific heat capacity.

Annand [9] was the first to propose a dimensionally consistent heat transfer model for internal combustion engines based on the Polhausen extension of the Reynolds analogy, by keeping the form of the equation and by looking for the appropriate parameters $a, b$ and $c$ (Eq. 6).

$$
N u=a \cdot R^{b} \cdot \operatorname{Pr}^{c}
$$


He suggested to use the cylinder bore (D) and the mean piston speed $\left(c_{m}\right)$ for the characteristic length and velocity, respectively. He neglected the Prandtl number effect to reduce calculation efforts at that time (1960s), since it is almost constant and around 0.7 for most of the gases. Annand fitted the model to the heat transfer measurements of Elser [3] and concluded that parameter $a$ should 40 have a value between 0.35 and 0.8 and that $b$ should be equal to 0.7. Parameter $a$ depends on the engine geometry and charge motion. Therefore, it can be used as a scaling factor to fit the model to a certain engine.

A second widely used model is that of Woschni [10, who followed Annand and based his model on Eq. 2, also with the Prandtl number lumped into the 45 parameter $a$. Woschni's model mainly differs from that of Annand in three aspects. First, Woschni took parameter $a$ and $b$ from models which describe the heat transfer of flows in tubes $(a=0.045, b=0.8)$. Secondly, he made assumptions on the gas properties to convert Eq. 1 and 2 into Eq. 7 (as described in 11) in order to calculate the heat flux as a function of only the 50 cylinder bore, the characteristic velocity, the cylinder pressure and temperature. The third and most important difference between the model of Woschni and that of Annand is the characteristic velocity. Woschni stated that an additional term is needed, representing the effect of the combustion on the heat transfer, for which he added the pressure difference between the fired and the motored 55 case.

$$
q=a \cdot D^{-0.2} \cdot p^{0.8} \cdot V^{0.8} \cdot T^{-0.53} \cdot\left(T_{\text {gas }}-T_{\text {wall }}\right)
$$

The assumptions made by Woschni in the derivation of Eq. 7 are only valid for air, making the extrapolation of the model to other gases not justified. Although these models seem to perform well for tradition fossil fuels, they do not provide accurate results for alternative fuels, e.g. hydrogen [12, 13, nor for ${ }_{60}$ new combustion types e.g. HCCI (homogeneous charge compression ignition) [14 16]. This is illustrated with Fig. 1 obtained from [13] that compares the measured heat flux trace with the predicted heat flux trace for hydrogen. The models are calibrated to correctly predict the peak value of the heat flux in the case of $\lambda=1.5$. When varying the equivalence ratio, the models over predict and 65 under predict the peak heat flux for leaner mixtures and richer mixtures, respectively. The most obvious possible reason is that these models are constructed using engine measurements with air and fossil fuels with comparable gas properties. Because the gas properties have not been varied over a wide range, they have not been incorporated properly in the current heat transfer models. Consequently, these models are unable to capture the effects of alternative fuels like hydrogen with very different gas properties. Neglecting the Prandtl number, for example, introduces an error. Although most gases have a comparable value for the Prandtl number (around 0.7), water vapor, a combustion product, has a Prandtl number around unity. The goal of this work is to investigate the

75 effect of the gas properties in Eq. 2 on the heat flux and to incorporate them accurately in a fuel-independent heat transfer model.

In order to construct a heat transfer model that is fuel-independent, new 


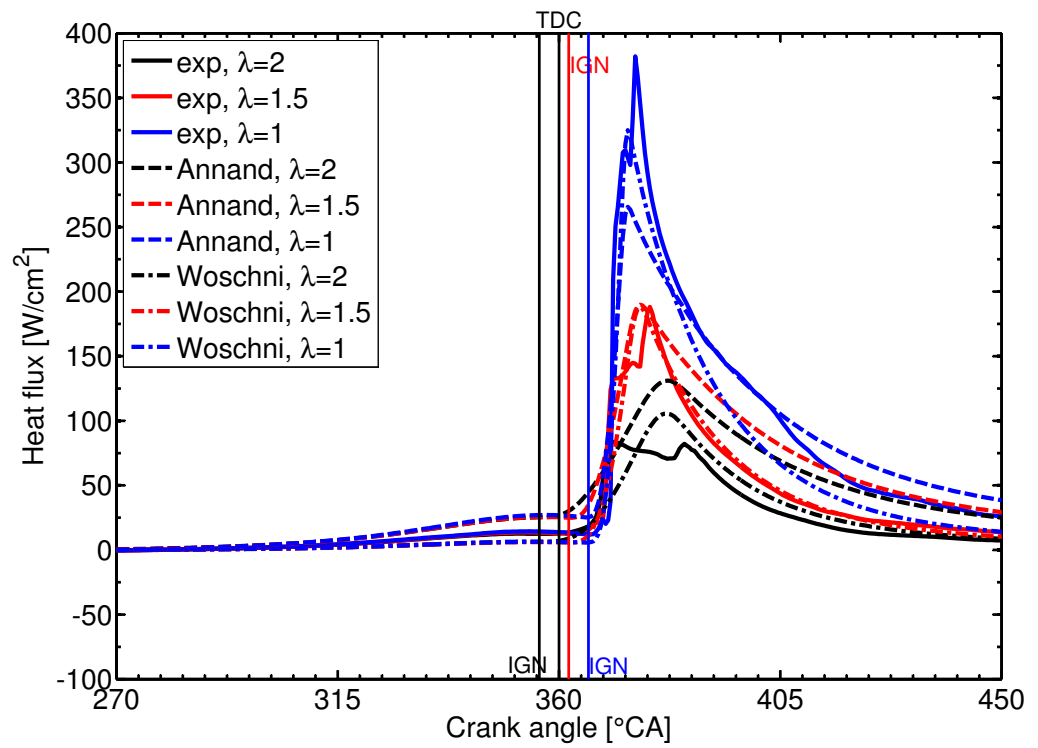

Figure 1: Comparison of heat flux measurements (exp) and model predictions (Woschni and Annand) for hydrogen when varying the equivalence ratio 13

engine measurements need to be executed. Not only the fuel needs to be varied in these measurements to have a range of gas properties, but also the engine so parameters need to be varied over a wide range to expand the validity of the model. Because of the multitude of parameters, the design of such an experiment needs to be carefully planned to be able to gain insight into the heat transfer process. This requires a thorough understanding of the mechanics responsible for the heat transfer and the impact of different fuels on the heat transfer. In

85 this work, a number of heat transfer measurements in SI engines published in the literature are reviewed. This review serves as the basis for a root cause analysis to identify the independent factors that affect heat transfer. Based on these factors, two experiments are set up according to the Design of Experiments methodology [17] that makes it possible to distinguish between the effect of the 90 gas properties and the engine settings and the interaction between them. The results of these measurements for motored operation are discussed in [1] and for fired operation in a companion paper [2]. 


\section{Review of heat transfer}

The review will be divided into two groups according to the operation of

95 and then those under fired operation. Under motored operation, the engine is driven by an electric drive and the gases inside the engine are only compressed and expanded, without combustion taking place. Such measurements allow the investigation of the effect of the gas properties and the gas flow without the factor in order to deduce which factors have an influence. These factors should be represented in the heat transfer models. The differences in sensor types and measurement locations will be indicated.

\subsection{Measurements under motored conditions}

Under motored operation, the spatial variation and influence of the following engine factors was investigated in the literature: the intake flow, the intake pressure, the engine speed and the compression ratio. An overview of the discussed measurements is given in Table 1 Table 1 is ordered chronologically, but the works from different authors from the same research institutions are grouped. Peak heat fluxes under motored conditions vary between 10 and $40 \mathrm{~W} / \mathrm{cm}^{2}$ for compression ratios around 10. The measured values of Boggs and Borman [18, 19] are much higher because the intake air was preheated up to $320^{\circ} \mathrm{C}$ to have the same initial conditions that enable HCCI combustion in their engine. Consequently, it is impossible to quantitatively compare their results with those of the others. However, their results have still been included in the review, because they thoroughly investigated the effect of the intake flow.

\subsubsection{Spatial variation}

Alkidas 24] measured the heat flux with eroding ribbon sensors at five different positions and investigated the influence of the measuring position. He ${ }_{120}$ showed that the heat flux starts to increase at the same time for all the positions. Consequently, the heat flux must mainly be driven by the bulk flow and temperature in the cylinder. This was confirmed by Nijeweme et al. [27] who also used eroding ribbon sensors. However, local gas velocity and turbulence also have an effect on the heat transfer, because there was spatial variation on 125 the peak of the heat flux.

\subsubsection{Influence of intake flow}

Overbye et al. [20, and Boggs and Borman [18, 19] used coaxial sensors to measure the heat transfer inside a CFR (Cooperative Fuel Research) engine with a shrouded intake valve, varying the shroud position to produce different ${ }_{130}$ flows and levels of turbulence. They found that the heat flux was higher for swirl flow than for tumble flow. Boggs and Borman [19] also used RTDs (resistance temperature detector) to measure the heat flux at 7 positions parallel to each other within $1 \mathrm{~mm}$ and defined an integral length scale and intensity for the measured heat flux, inspired by methods for velocity measurements. A 


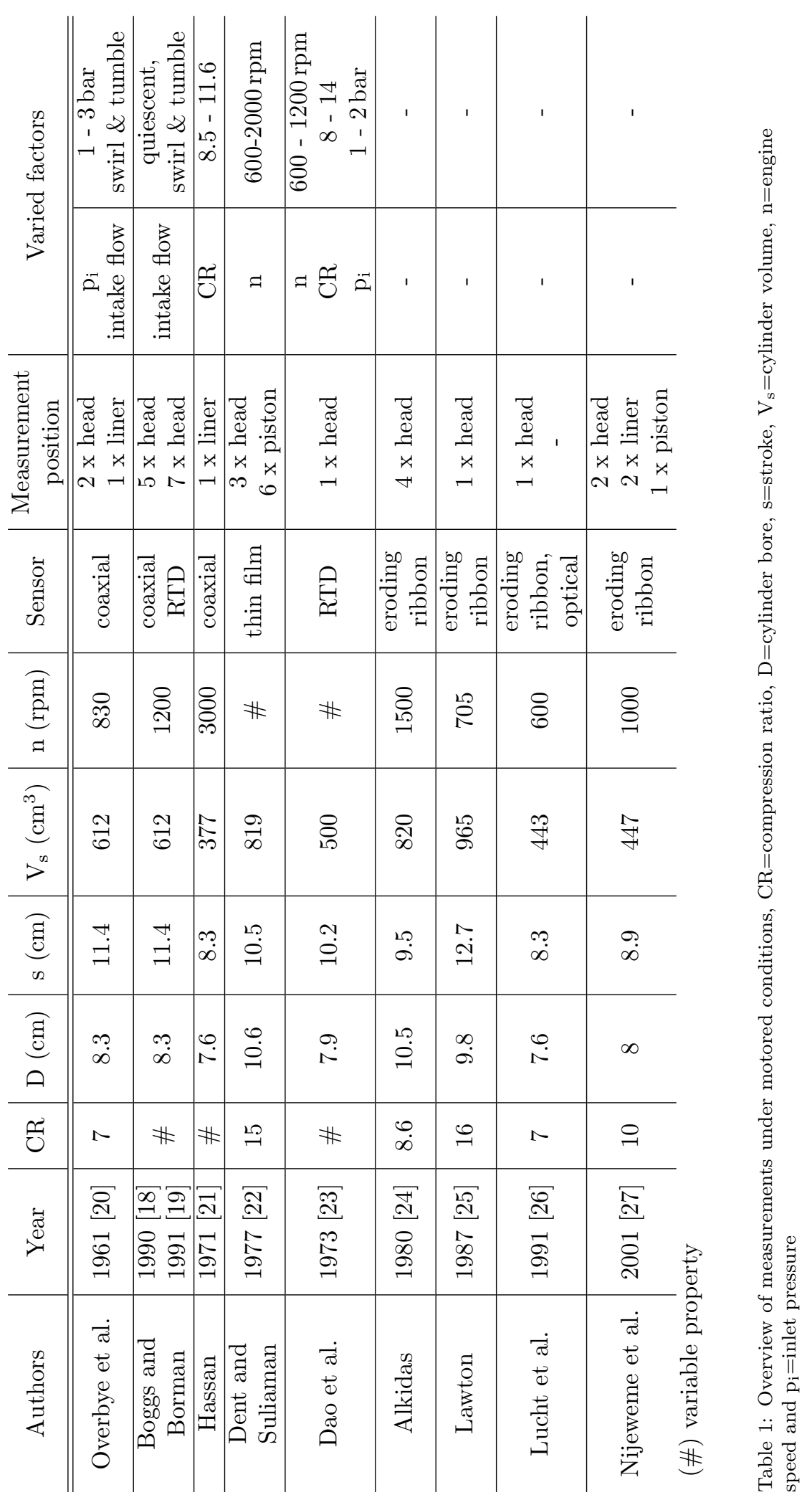


large length scale means that the heat flux of measurement positions far from each other are strongly correlated. A high intensity means that the heat flux at a certain measurement position is strongly fluctuating. They did not state it that explicitly, but three arguments can be found in their publication that demonstrate that the structure of the intake flow has an influence on the heat

140 transfer process. First, the heat flux in the swirl case had the largest length scale and the lowest intensity, because it is a well-structured flow with little turbulence. Second, the heat flux caused by a quiescent flow had the smallest length scale because of the absence of a structured flow. Third, the heat flux generated by a tumble flow had the highest intensity because of the high turbu-

145 lence intensity of the flow. Dao et al. 23 recorded the temperature from two RTDs during two consecutive cycles, one with and one without the induction of fresh gases. Their measurements showed that the heat flux of the first cycle was not only higher during the compression stroke, but also during the expansion stroke. This indicates that the turbulence and gas motion caused by the induction process persists throughout the entire engine cycle, being confirmed by recent investigations of Burluka et al. 28] in an optically accessible engine.

\subsubsection{Influence of intake pressure}

Overbye et al. 20] varied the intake manifold pressure and found an increase in the heat transfer with a higher pressure. Both the heat flux from the cylinder 155 walls during the intake and exhaust stroke and the heat flux to the cylinder walls during the compression and expansion stroke were higher. Overbye et al. did not explain the observations, but the first two effects can be explained by the higher pressure difference across the valves, leading to a faster gas flow and hence a higher heat flux from the cylinder walls. The higher heat flux to the cylinder walls during the compression and expansion stroke must be caused by a larger temperature difference between the gas and the wall. Dao et al. 23] confirmed that the peak heat flux increased with an increasing intake pressure.

\subsubsection{Influence of engine speed}

All researchers agree on the fact that the heat flux increases if the engine 165 speed is higher because of an increased gas velocity. Hassan [21] (with a coaxial thermocouple) and Dao et al. 23] demonstrated that the peak values of the heat flux increased. Dent and Suliaman [22] (with a thin film sensor) showed that the heat flux was only significantly higher around TDC within an interval of $90^{\circ} \mathrm{CA}$. The piston speed in this interval is lower than in other parts of the cycle, but the gas velocity must still be significant because of its inertia.

\subsubsection{Influence of compression ratio}

Hassan 21] and Dao et al. 23] demonstrated that the peak values of the heat flux increased with an increasing compression ratio because of a higher incylinder pressure which results in a higher gas temperature. Hassan [21] varied

175 the compression ratio between 8.5 and 11.6 , observing a $10 \mathrm{~W} / \mathrm{cm}^{2}$ increase in the peak heat flux (30\% increase). Dao et al. 23] increased the compression 
ratio from 8 to 14 , noticing the peak heat flux to change with $25 \mathrm{~W} / \mathrm{cm}^{2}(70 \%$ increase).

\subsection{Measurements under fired conditions}

180 will be reviewed. In the literature, the spatial variation and effect of the engine speed, ignition timing, compression ratio, load, mixture richness, intake flow and volumetric efficiency have been examined. It is more difficult to investigate the effect of the parameters separately than it was the case for motored conditions. fects. The overview of the fired measurements is given in Table 2. Again, the publications are ordered chronologically, but those of authors belonging to the same research institutes are put together.

\subsubsection{Spatial variation}

190

Two firm conclusions can be drawn about the spatial variation in the heat flux of a SI engine. First, the heat flux at a certain location starts to increase when the flame arrives 24, 30, which the cited authors ascribe to the sudden temperature increase. Second, there is a large variation in the maximum heat flux across the in-cylinder surfaces [30, 33, 34. A clear trend in that variation decreases away from the cylinder head as shown by Enomoto et al. 33 who measured the heat flux at 10 different heights with a coaxial sensor. This can be explained by the fact that lower positions are only shortly exposed to the combustion gases (at lower temperatures). For the other surfaces, significant 200 spatial variation in the heat flux is observed in literature, but without clear trends. These variations are caused by local differences in the gas velocity, the turbulence level and the gas and wall temperature.

\subsubsection{Influence of engine speed}

Alkidas 24] and Enomoto et al. 33] observed that the peak and total cycle heat flux increased with engine speed which is ascribed to an increase in gas velocity and turbulence. The increase in heat transfer occurred mostly in the beginning of the expansion stroke, probably because of the higher gas temperatures in that part of the cycle. The measurements of Enomoto et al. [33. on the piston and cylinder head showed, however, a decrease in relative importance of the heat transfer (expressed as a percent of the fuel's chemical energy) with increasing engine speed. Gilaber and Pinchon [38] observed, similarly, that the total cycle heat loss decreased with an increasing engine speed, although the peak heat flux increased. This is caused by the fact that the cycle duration decreases. Heywood [4] confirmed this trend with thermodynamic cycle sim-

215 ulations. Choi et al. 39] showed that the measured wall surface temperature of the cylinder head, piston and valves increased with engine speed as well. On the other hand, the temperature swing (i.e. the difference between the minimum and maximum temperature) of the cylinder head during an engine 


\begin{tabular}{|c|c|c|c|c|c|c|c|c|c|c|c|c|c|}
\hline \multirow{2}{*}{ 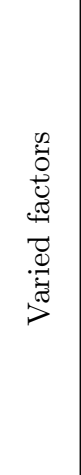 } & 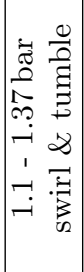 & 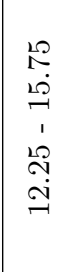 & 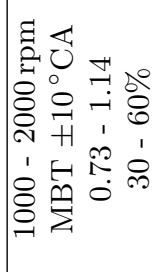 & 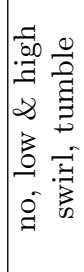 & 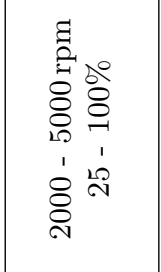 & 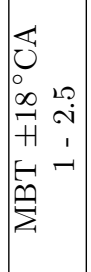 & 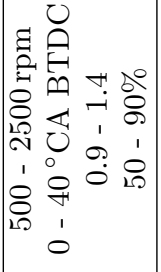 & 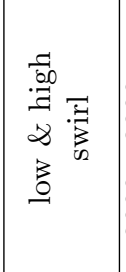 & 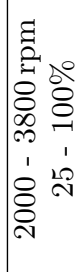 & 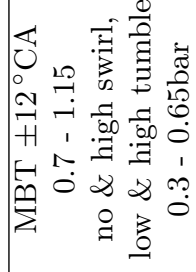 & \begin{tabular}{c|}
$\sim$ \\
$\stackrel{-}{1}$ \\
1 \\
$\infty$ \\
0
\end{tabular} & $\begin{array}{l}\vec{H} \\
\infty \\
1 \\
-1\end{array}$ & \\
\hline & 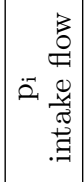 & 窟 & 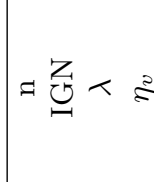 & 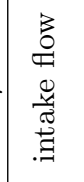 & $=\stackrel{\widetilde{Z}}{\widetilde{\sigma}}$ & 否 & 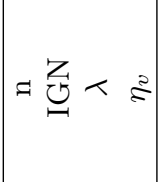 & 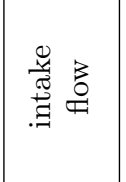 & $=\underset{\widetilde{\pi}}{0}$ & 芯 & $x$ & $<$ & \\
\hline 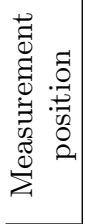 & 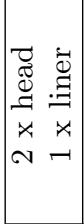 & $\begin{array}{l}\vec{Z} \\
\mathbb{\Xi} \\
-\underline{x} \\
-1\end{array}$ & 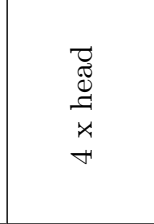 & 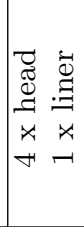 & 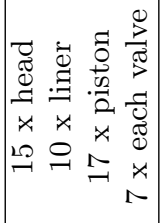 & 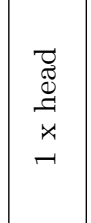 & 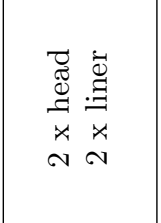 & 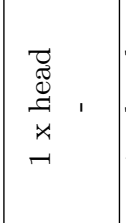 & 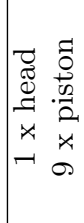 & 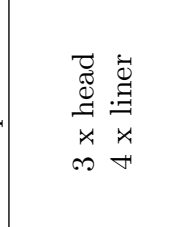 & $\begin{array}{l}\stackrel{\vec{\Xi}}{\Xi} \\
\ddot{y} \\
\ddot{\forall}\end{array}$ & 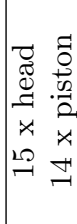 & \\
\hline 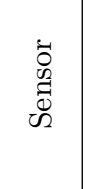 & 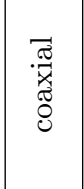 & 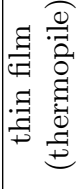 & 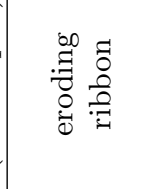 & 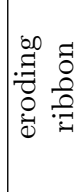 & $\begin{array}{l}. \bar{\pi} \\
\text {. } \\
\text { ठํ } \\
0\end{array}$ & 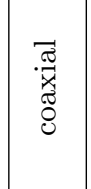 & 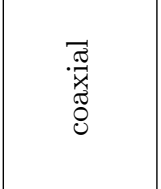 & 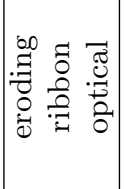 & 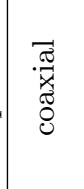 & 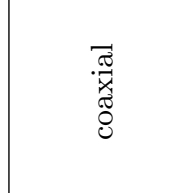 & 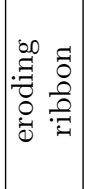 & 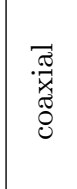 & \\
\hline 刍 & $\begin{array}{l}0 \\
\mathbb{Z} \\
\mathbb{\pi} \\
0 \\
0 \\
0 \\
0 \\
0.9\end{array}$ & $a$. & 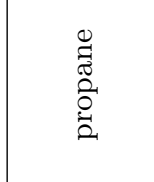 & $\begin{array}{l}0 \\
\mathbb{Z} \\
\mathbb{0} \\
0 \\
0 \\
0 \\
0 \\
.9\end{array}$ & 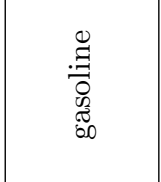 & 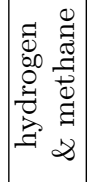 & 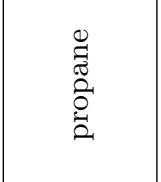 & 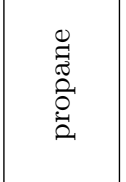 & 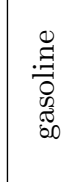 & 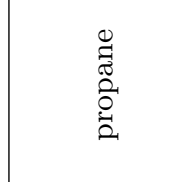 & $\begin{array}{l}0 \\
: \\
0 \\
0 \\
0 \\
\infty \\
\infty\end{array}$ & 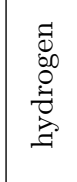 & \\
\hline 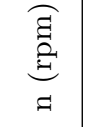 & ஜి & : & \# & \&્م & \# & 总 & \# & 8 & \# & 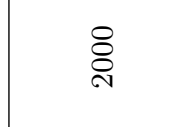 & 总 & $\underset{\overbrace{}}{\stackrel{\sim}{~}}$ & \\
\hline$\underbrace{\text { है }}_{p^{\infty}}$ & $\frac{7}{\vartheta}$ & 㹲 & $\underset{\infty}{\stackrel{N}{\infty}}$ & 电 & i⿱乛龰 & ஓ্ł & $\vec{\infty}$ & $\stackrel{\Re}{\forall}$ & $\underset{10}{8}$ & $\underset{f}{\&}$ & है & 戹 & \\
\hline$\underbrace{\stackrel{\text { व्य }}{0}}_{n}$ & $\stackrel{\rightleftarrows}{ت}$ & $\stackrel{\overrightarrow{+}}{+}$ & $\stackrel{10}{\circ}$ & $\begin{array}{l}10 \\
\infty \\
\infty\end{array}$ & $\stackrel{\vec{\infty}}{\infty}$ & $\begin{array}{l}\infty \\
\infty \\
\infty\end{array}$ & $\stackrel{\ddot{\infty}}{\infty}$ & $\stackrel{\infty}{\infty}$ & a. & $\vec{\infty}$ & 0 & $\sigma$ & \\
\hline$\underbrace{\text { द्व }}_{0}$ & $\stackrel{\Re}{\infty}$ & L̊ & $\stackrel{20}{\stackrel{0}{0}}$ & $\tilde{\sigma}$ & $\stackrel{\infty}{\infty}$ & $\begin{array}{l}10 . \\
\infty\end{array}$ & $\stackrel{0}{\stackrel{0}{N}}$ & $\stackrel{0}{\stackrel{0}{N}}$ & $\sim$. & $\stackrel{\circ}{\infty}$ & $\stackrel{\dot{\infty}}{\infty}$ & $\underset{\infty}{+}$ & \\
\hline 응 & 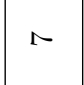 & $\stackrel{\substack{\infty \\
\infty}}{\infty}$ & $\stackrel{0}{\infty}$ & 0 & $\stackrel{\infty}{\infty}$ & $\stackrel{100}{\infty}$ & $\stackrel{\infty}{\rightarrow+}$ & $\curvearrowright$ & $\tilde{\sigma}$ & 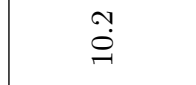 & $\exists$ & $\stackrel{\mathcal{I}}{ }$ & \\
\hline 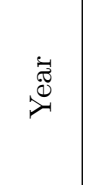 & 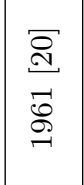 & 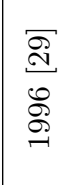 & 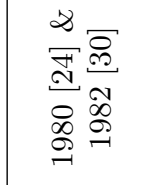 & $\begin{array}{l}\vec{\sigma} \\
\vec{\sigma} \\
\stackrel{\sigma}{\sigma}\end{array}$ & 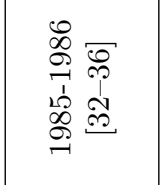 & 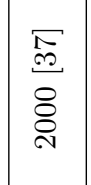 & $\begin{array}{l}\infty \\
\stackrel{\infty}{\infty} \\
\infty \\
\infty \\
\stackrel{9}{=}\end{array}$ & $\begin{array}{l}\mathscr{Q} \\
\vec{\alpha} \\
\vec{\sigma}\end{array}$ & 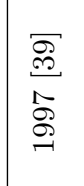 & $\begin{array}{l}\text { 웨 } \\
\stackrel{\leftrightarrow}{\circ} \\
\stackrel{\circ}{-}\end{array}$ & 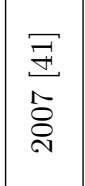 & 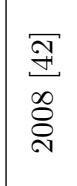 & 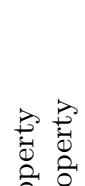 \\
\hline 吾 & 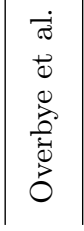 & 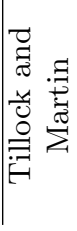 & 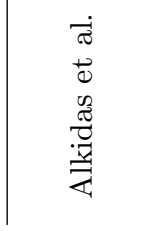 & 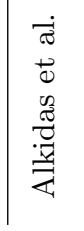 & 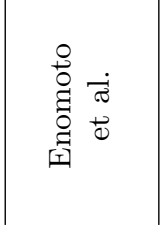 & 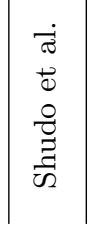 & 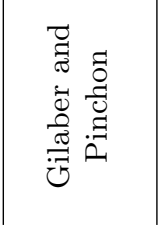 & 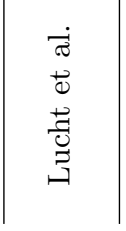 & 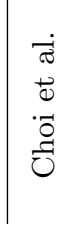 & 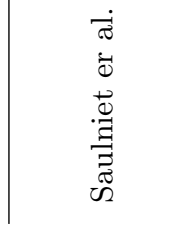 & 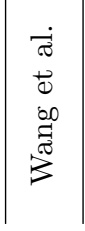 & 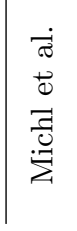 & 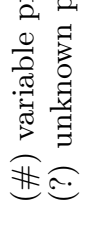 \\
\hline
\end{tabular}


cycle decreased because of the shorter burn duration. One has to be careful in interpreting their heat flux results, because these are up to 4 times higher $\left(2000 \mathrm{~W} / \mathrm{cm}^{2}\right)$ than what is measured in other SI engines $\left(500 \mathrm{~W} / \mathrm{cm}^{2}\right)$, possibly indicating a signal processing error.

\subsubsection{Influence of ignition timing}

Alkidas 24] varied the spark timing around MBT with $10^{\circ} \mathrm{CA}$ at both sides, 225 showing that it influenced both the rise and the peak value of the heat flux. The flux at the measurement location started to rise earlier with an advanced ignition timing because of the earlier flame arrival. The heat flux peak increased because of a higher gas temperature around TDC. These results were confirmed by others [37, 38, 40, 41. The effect of the ignition timing will have an interaction with almost all the other factors discussed below, because an engine is always run with an optimal timing (ideally MBT: minimum spark advance for Maximum Brake Torque) and changing an engine parameter leads to a different optimal ignition timing.

\subsubsection{Influence of compression ratio}

235 According to Heywood [43] several operational properties change with an increasing compression ratio $(\mathrm{CR})$ : the gas pressure, surface to volume ratio around TDC, peak burned gas temperature and gas motion increase, the combustion is faster and the gas temperature late in the expansion stroke decreases. The first five properties increase the heat transfer, the last one decreases it.

240 According to Heywood, total cycle heat loss in an SI engine decreases with an increasing compression ratio until a $\mathrm{CR}$ of 10 because the lower gas temperature in the expansion stroke dominates the other effects. The other trends are dominating for higher compression ratios and therefore total cycle heat loss starts to increase for an increase in CR above 10. These simulation observations were,

245 however, never confirmed with measurement results. The effect of the surface to volume ratio is also present when the swept volume is altered. Engines with a larger swept volume have a smaller surface to volume ratio, which reduces the heat loss. Because the surface to volume ratio at TDC is also determined by the piston surface shape, this also has a significant effect on the heat transfer 2504 .

\subsubsection{Influence of engine load}

In a classical SI engine, the load is controlled by changing the in-cylinder mass by means of a throttle in the intake manifold, keeping the mixture richness around the stoichiometric value. Enomoto et al. 33] and Enomoto and 255 Furuhama 34 showed that the peak and total cycle heat flux increased with the load. Expressed as a fraction of the fuel's chemical energy, the heat transfer decreased as it was the case for an increasing engine speed. These results were confirmed by the cycle simulation results of Heywood [43. Choi et al. 39] found that the wall temperature and the temperature swing of the cylinder head and 260 valves increased as well. When the load was increased from $20 \%$ to $100 \%$, the temperature swing of the cylinder head increased from $5 \mathrm{~K}$ to $9 \mathrm{~K}$. The higher 
component temperatures can be explained by the fact that the gas temperature increases due to the decreased share of the heat losses. For small throttle openings, there will be a counteracting influence of the turbulence, because increasing the throttle opening will decrease the turbulence level and, hence, the heat flux.

\subsubsection{Influence of mixture richness}

Varying the mixture richness is an alternative to changing the engine load, so this section is related to the one above. This demonstrates how difficult it is to investigate the different parameters separately. Decoupling the effect of the mixture richness from that of the engine load could be possible by the use of a throttle, but this would entail the effect of the turbulence. Furthermore, the mixture richness has a large influence on the flame propagation speed. Thus, the optimal ignition timing is affected, having an influence as well.

Unless specified otherwise, the reported investigations used wide open throttle and MBT-timing. According to the simulation results of Heywood [4], the peak heat flux reaches its maximum at the equivalence ratio for maximum power (for hydrocarbon fuels this is at $\phi=1.1$ or $\lambda=0.9$ ). The total cycle heat loss relative to the fuel's chemical energy reaches its maximum for stoichiometric 280 combustion. Several authors investigated the effect of the air-to-fuel equivalence ratio on the heat flux, both in fossil fuelled engines [29, 30, 38, 40, and hydrogen fuelled ones 37, 42. It is difficult to quantitatively compare the results of different authors due to differences in the engines and operation modes. However, Fig. 2 is an attempt to compare the effect of the air-to-fuel equivalence ratio on the heat flux observed by Alkidas et al. 30, Saulnier et al. 40 and Tillock et al. 29. The peak heat flux has been normalized and a cross section of the engine is added to show the number of valves and measurement location (first letter of author name). All the investigations show a maximum in the peak heat flux as a function of the mixture richness. All the data indicates that 290 the maximum occurs around the stoichiometric air-to-fuel ratio, but not enough measurement points are available to accurately determine the equivalence ratio at which this maximum occurs to confirm the statement of Heywood. The fact that there is a maximum in the curve as a function of the air-to-fuel equivalence ratio can be attributed to two phenomena. The first one is the adiabatic temperature, which is the highest for stoichiometric mixtures and decreases when the mixture richness is decreased or increased. The second one is the flame speed, which is the highest for richer mixtures. However, this effect is opposed to that of the ignition timing, being retarded for richer mixtures. This is confirmed by the measurements of Wang et al. 41, using a constant ignition timing and not finding a maximum in the peak heat flux around stoichiometric mixtures (between 1.2 and 0.8 ).

\subsubsection{Influence of intake flow}

Changing the intake flow configuration changes the turbulence level and mean gas velocity, as discussed above for the motored measurements. Compared to those motored measurements, it is even more difficult to distinguish 

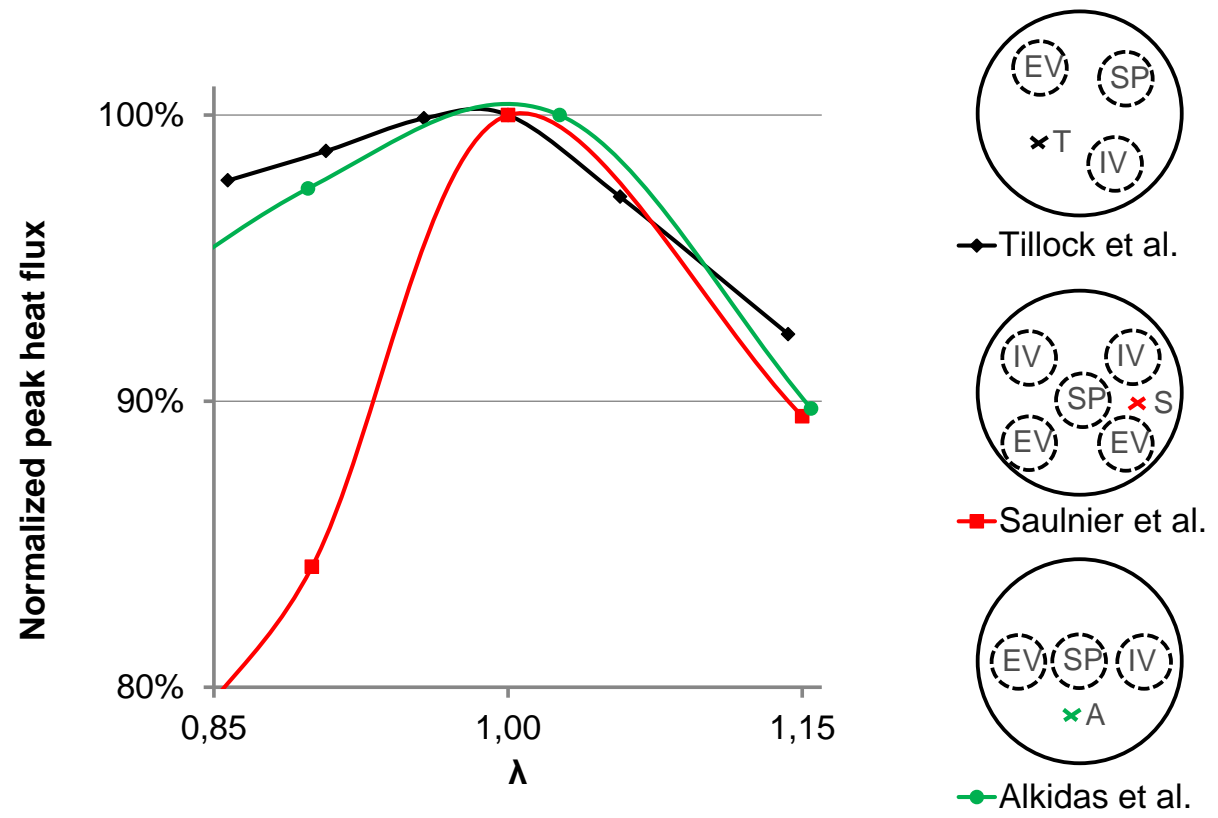

Figure 2: The normalized peak heat flux as a function of the air-to-fuel equivalence ratio, with indication of the heat transfer measurement location ( $\mathrm{T}, \mathrm{S}$ and $\mathrm{A})$, the intake and exhaust valve (IV and EV) and the spark plug (SP)

between the two effects, because there is an extra interaction with the combustion process. The fact that a higher turbulence caused an increase in the heat flux was already mentioned in some of the sections above, when a throttle was used. Alkidas and Suh [31 and Saulnier et al. 40. compared several swirl and tumble flows with baseline configurations and showed that it had a significant effect on the heat flux. However, no clear conclusions can be made since different trends were observed and it is difficult to compare the intake flow configurations between the two investigations. Lucht et al. 26] investigated the effect of two flow configurations on the heat flux at the head: low-swirl, which seems to be a tumble flow, and high-swirl. The high-swirl configuration generated the highest peak in the heat flux trace, but had a lower heat flux at the end of the expansion stroke. The first is probably caused by a higher mean gas velocity. The latter could be explained by a lower turbulence level or by a lower gas temperature caused by a faster combustion process. In all references 320 cited above, the influence of the intake flow is less clear compared to motored measurements because of the influence of combustion. It seems that the effects caused by combustion dominate those of the gas flow. The measurements of Overbye et al. [20] did not even show a great difference in the heat flux if the shroud of the intake valve was changed in contrast to their measurements under 


\subsubsection{Influence of volumetric efficiency}

There are two possibilities to change the volumetric efficiency of the engine: throttling or supercharging. Both have an effect on the engine load, so this section is related to that of a changing load. Overbye et al. 20] found that the manifold pressure $(0.27 \mathrm{bar})$. Saulnier et al. [40] varied the intake manifold pressure between 0.3 and 0.65 bar, probably with a throttle (not specified in the paper), and found that the heat flux increased linearly with the increasing intake pressure. Alkidas and Myers 30 and Gilaber and Pinchon 38 found transfer (both peak and total cycle), but they did not report whether this was obtained by supercharging or throttling. Changing the volumetric efficiency has the same effect on the heat transfer as an increasing load because it also affects the in-cylinder mass and, hence, the released energy.

\section{Identification of factors influencing heat transfer}

The review above demonstrated that the heat transfer in SI engines rarely has been investigated in a systematic way and that it is difficult to make firm conclusions. For these reasons, it can be concluded that new heat transfer measurements are necessary. In order to make statistically motivated conclusions, these measurements should be executed according to the Design of Experiments methodology [17. The first step is the identification of the dependent and independent variables. The dependent variable in this case is the heat flux (q) and the possible independent factors were found using a root cause analysis based on the literature review and the current experimental equipment available.

\subsection{Experimental equipment}

The engine that will be used for the heat transfer measurements, is a fourstroke single-cylinder SI engine based on a CFR engine operated at a constant speed of $600 \mathrm{rpm}$. A cross section is given in Fig. 3, showing the possible sensor positions in the cylinder wall. It is equipped with port fuel injection and 355 has a variable compression ratio. Two types of injectors are available in the intake manifold, one for gaseous fuels and one for liquid fuels. The injection and ignition are controlled by a MoTeC M4Pro electronic control unit. The compression ratio has to be kept below 10, because the moving piston would otherwise damage the heat flux sensor. The details of the engine are given in Table 3. It has been overhauled, resulting in a larger bore diameter and different valve timings compared to older publications.

The heat flux and wall temperature are measured at positions P2, P3 and P4 with a Vatell HFM-7 sensor which consists of a thermopile (heat flux signal) and an RTD (resistance temperature detector). Vatell claims that the sensor has a 365 response time of $17 \mu \mathrm{s}$. The Vatell AMP-6 amplifier is used as a current source 


\begin{tabular}{|c|c|}
\hline Bore & $83.06 \mathrm{~mm}$ \\
\hline Stroke & $114.2 \mathrm{~mm}$ \\
\hline Connecting rod length & $254 \mathrm{~mm}$ \\
\hline Swept volume & $618.8 \mathrm{~cm}^{3}$ \\
\hline IVO & $10^{\circ} \mathrm{CA}$ ATDC \\
\hline IVC & $19^{\circ} \mathrm{CA}$ ABDC \\
\hline EVO & $39^{\circ} \mathrm{CA} \mathrm{BBDC}$ \\
\hline EVC & $12^{\circ} \mathrm{CA}$ ATDC \\
\hline
\end{tabular}

Table 3: CFR-engine properties
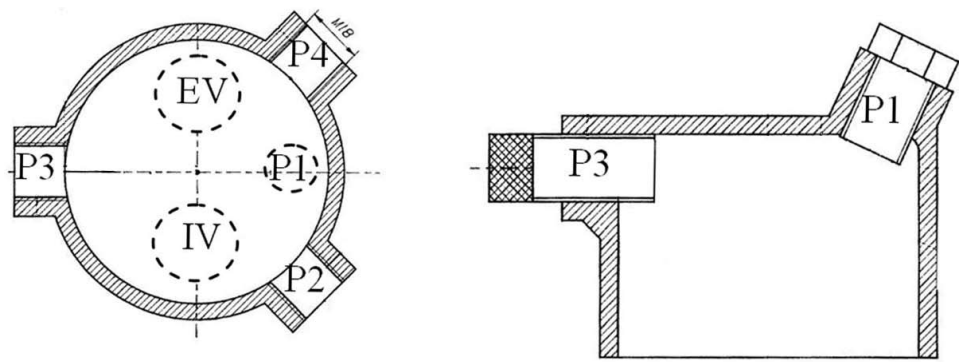

Figure 3: Cross section of the CFR engine, P1 spark plug position, P2-4: possible sensor positions, IV: intake valve, EV: exhaust valve

for the RTD and as an amplifier for both output signals. The measurement positions are at the same height in the cylinder wall and are equally distributed around the circumference of the cylinder. The spark plug is mounted in position $\mathrm{P} 1$. In-cylinder pressure is measured with a water-cooled Kistler 701A piezoelec-

sensor (mounted in P4 or P2). Inlet and outlet pressure are measured with two Kistler 4075A10 piezoresistive pressure sensors. The inlet pressure is used to reference the in-cylinder pressure. Gas flows are measured with Bronkhorst Hi-Tec F-201AC (gas) and F-106BZ (air) flow sensors. Liquid fuel mass flow rate is measured gravimetrically. Finally, K-type thermocouples are used to measure coolant, oil and inlet and exhaust gas temperatures. All the signals are acquired with a National Instruments PXI system. Crank angle resolved signals (HFM and pressure signals) are acquired synchronously with a PXI-6143 S-series card every $0.5^{\circ} \mathrm{CA}$ (sample rate of $7.2 \mathrm{kHz}$ ) during 100 consecutive cycles. The other signals are averaged over time and acquired with a PXI-6224 M-series card at a sampling rate of $1 \mathrm{~Hz}$.

\subsection{Root cause analysis}

As stated earlier, the independent factors that influence the heat transfer are identified using a root cause analysis based on the literature review and the experimental equipment described above. The result of the root cause analysis 


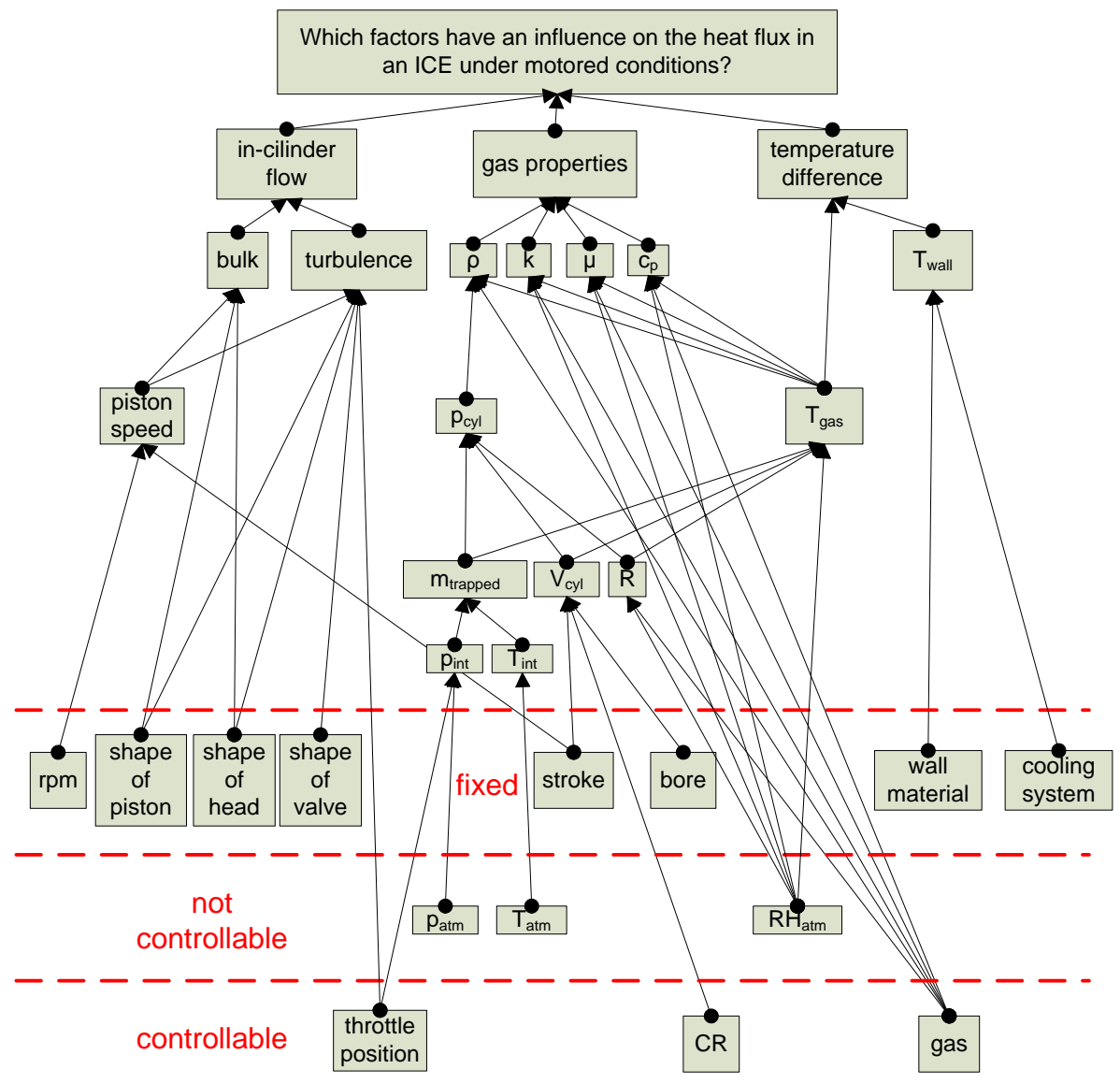

Figure 4: Root cause analysis to identify the factors to be investigated under motored operation

Three main groups were identified to have an effect on the heat flux: incylinder flow, gas properties and temperature difference between the combustion gases and the cylinder wall. The first two are represented by the convection coefficient in the modelling approach suggested by Annand. Those three groups were further expanded to obtain the factors that can actually be changed on the test engine. The pathways from those factors to the top can be used to explain observed trends in the heat flux. The different factors are grouped into three categories: unchangeable (fixed on the test engine), uncontrollable (atmospheric properties) and controllable factors. These are the independent factors that affect the heat transfer. The atmospheric conditions do not change 


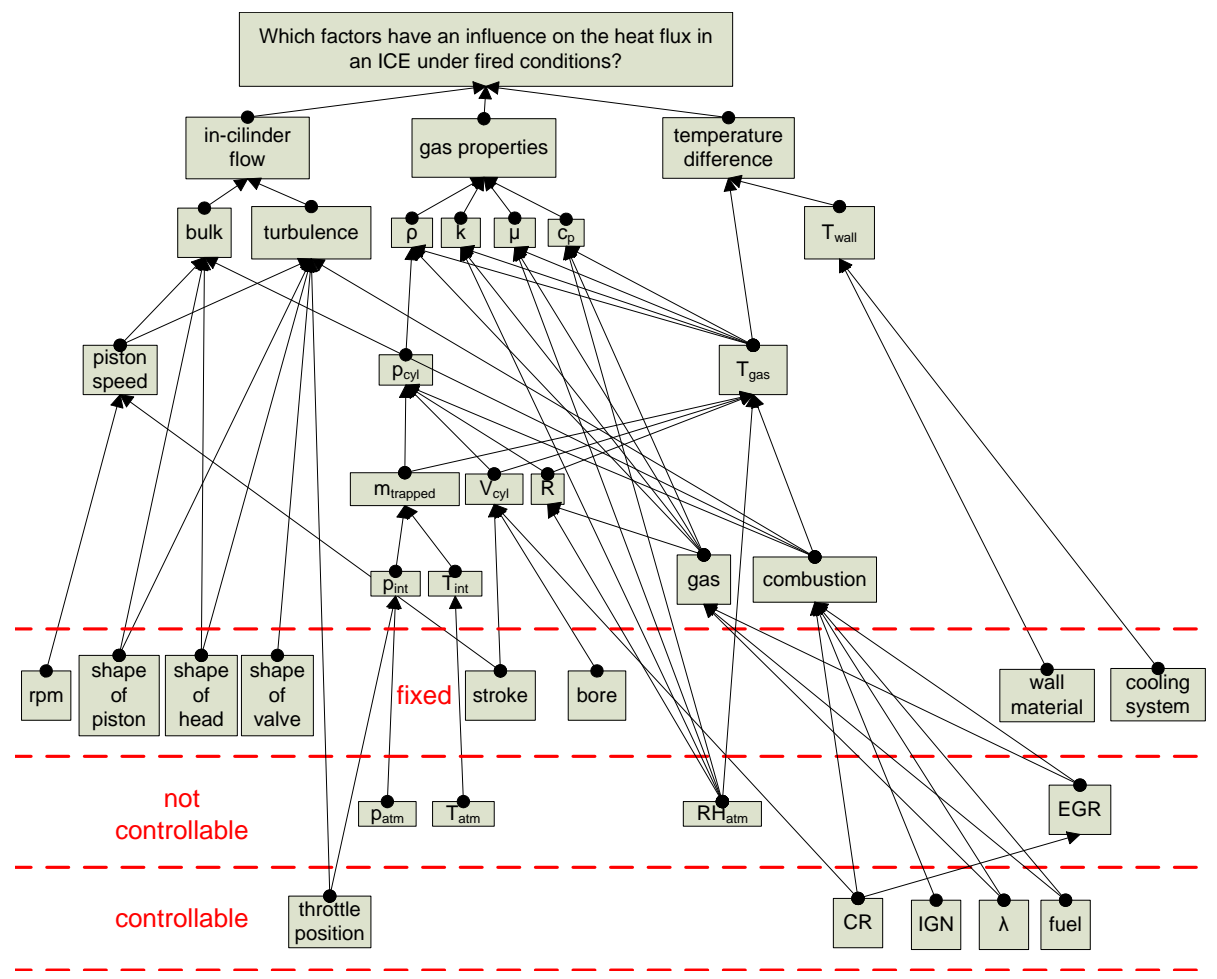

Figure 5: Root cause analysis to identify the factors to be investigated under fired operation

during the experiments, so these can be neglected. Consequently, only the last category is investigated. For motored operation, the root cause analysis resulted in the definition of three independent factors: the throttle position (TP), the compression ratio (CR) and the injected gas (type and quantity). For fired operation, an additional factor was defined (the ignition timing (IGN)) and the factor gas was split into fuel and equivalence ratio $\lambda$ ) so that a total of 5 factors was investigated. Because no significant spatial variation was observed under motored operation, this is not considered as an independent factor and the heat flux will only be measured in one location. However, under fired operation the 405 measurement location is an independent factor, so the heat flux will be measured at all three available locations. The engine load is considered as a dependent factor in this work and it is not shown in Fig 5 . Some authors in literature (see above) did investigate the effect of the load on the heat flux, but the load is actually a dependent variable itself, being influenced by all the controllable factors. 


\section{Experimental design}

As stated before, the experiment will be designed according to the Design of Experiments methodology. To be able to distinguish whether the fuels affect the heat flux because of their gas properties or because of their combustion characteristics, two kinds of experiments were designed. First, different inert gases were injected in the intake manifold of the engine under motored operation to investigate the effect of the gas properties without the influence of combustion. The combined effect of the gas properties and combustion was investigated under fired operation by using three fuels (hydrogen, methane and methanol). For 420 each experiment, the number of levels for each factor has to be determined and the best design has to be chosen.

\subsection{Experimental design under motored conditions}

An overview of the number of levels that were run for each factor under motored operation is given in Table 4. Since the first two factors are of the continuous type, they were given two levels to vary between their extreme values. For some gases, the heat flux has been measured for intermediate throttle positions (4) at one compression ratio. These can be used to investigate nonlinearities in the effect of TP which is expected to be present. No intermediate measurements were added for the compression ratio, since initial measurements

${ }_{430}$ in the engine on air with wide open throttle (WOT) showed that the effect of the compression ratio is linear in the range between 6 and 10 .

\begin{tabular}{c|c|c} 
factor & level & level code \\
\hline \multirow{2}{*}{$\mathrm{TP}$} & fully closed throttle (FCT) & -1 \\
& wide open throttle (WOT) & 1 \\
\hline \multirow{2}{*}{$\mathrm{CR}$} & 8 & -1 \\
& 10 & 1 \\
\hline \multirow{5}{*}{ gas } & 20 vol\% helium & 1 \\
& 50 vol\% helium & 2 \\
& 80\% vol argon & 3 \\
& $67 \%$ vol $\mathrm{CO}_{2}$ & 4 \\
& 100 vol\% atmospheric air & 5 \\
& 75 vol\% pressurized air & 6
\end{tabular}

Table 4: Overview of the factors' levels under motored operation

For the injected gas, it was examined whether the gas properties themselves could be used as the independent variables, since the ANOVA (analysis of variance) would directly indicate which of them are most significant. However, 435 this was not possible, since not enough inert gases could be identified to have a sufficient number of combinations of the factors to study their main effects. Therefore, the gas factor was defined as a categorical one and three inert gases were chosen, because they have a certain property that differs significantly compared to air. The gas properties of the used gases are given in Table 5 for two 
temperatures and were determined as a function of temperature with polynomials out of the DIPPR [44] database and with the mixing rules described in [45]. First, helium is chosen because of its high thermal conductivity and heat capacity. Second, argon is selected because of its high dynamic viscosity and low heat capacity. Finally, $\mathrm{CO}_{2}$ was used because it has a slightly higher Prandtl number 445 and low dynamic viscosity. In the introduction, it was mentioned that there is very little variation in the Prandtl number of gases and the largest variation in the experiment was actually obtained by varying the helium content in air (see below).

\begin{tabular}{c|c|c|c|c|c}
$\mathrm{T}[\mathrm{K}]$ & gas & $\mathrm{k}[\mathrm{W} / \mathrm{mK}]$ & $\mu[$ Pa.s.10 & $\mathrm{c}_{\mathrm{p}}[\mathrm{J} / \mathrm{kgK}]$ & Prandtl \\
\hline \multirow{4}{*}{300} & argon & 0.02 & 2.30 & 520 & 0.66 \\
& air & 0.03 & 1.87 & 993 & 0.71 \\
& helium & 0.15 & 2.00 & 5193 & 0.67 \\
& $\mathrm{CO}_{2}$ & 0.02 & 1.50 & 847 & 0.70 \\
\hline \multirow{3}{*}{700} & argon & 0.03 & 4.33 & 520 & 0.67 \\
& air & 0.05 & 3.33 & 1074 & 0.70 \\
& helium & 0.28 & 3.60 & 5193 & 0.67 \\
& $\mathrm{CO}_{2}$ & 0.05 & 3.09 & 1127 & 0.72
\end{tabular}

Table 5: Gas properties of the used gases 44 ]

The gas levels in Table 4 define the amount of inert gas, the rest of the mixture consists out of atmospheric air. It was not possible to fill the engine entirely with a pure inert gas, because the amount of gas that can be injected is limited by the maximum flow rate through the injector (gas dependent) and the engine cycle duration. For argon and $\mathrm{CO}_{2}$, the maximum achievable volume percentages in atmospheric air for the WOT cases were $80 \mathrm{vol} \%$ and $67 \mathrm{vol} \%$.

${ }_{455}$ However, two intermediate helium mixtures were tested (20 and $50 \mathrm{vol} \%$ of helium in atmospheric air), because the thermal conductivity of a helium-air mixture already significantly increases with a small volume percentage of helium in contrast to the heat capacity. As a consequence, the Prandtl number drops when the helium content is increased from the value of air $(0.7$ at $293 \mathrm{~K})$ over 0.56 for a $20 \mathrm{vol} \%$ mixture to a minimum of 0.46 for a $50 \mathrm{vol} \%$ mixture, see Table 6. Additional mixtures of helium and air ( 75 and $100 \mathrm{vol} \%$ of helium) were injected, but only at a compression ratio of 8 and at certain throttle positions because of the limited availability of the gas.

Since injecting a high amount of gas in the engine increases the trapped mass (especially for small throttle openings) compared to the natural aspiration of atmospheric air, an extra level of the gas factor was added by injecting an extra amount of air from a pressurized tank at the same pressure as the other gases ( 3 bar absolute) to result in a total of 6 levels for the gas factor. For the extra air level, the maximum achievable value of $75 \mathrm{vol} \%$ pressurized air in 470 atmospheric air was used. The atmospheric properties were constant during the experiments, so this did not affect the results. 


\begin{tabular}{c|c|c|c|c|c}
$\mathrm{T}[\mathrm{K}]$ & gas & $\mathrm{k}[\mathrm{W} / \mathrm{mK}]$ & $\mu[$ Pa.s.10 $]$ & $\mathrm{c}_{\mathrm{p}}[\mathrm{J} / \mathrm{kgK}]$ & Prandtl \\
\hline \multirow{3}{*}{300} & 20vol\% helium & 0.04 & 1.92 & 1133 & 0.56 \\
& 50vol\% helium & 0.07 & 2.01 & 1503 & 0.46 \\
& 80vol\% argon & 0.02 & 2.22 & 593 & 0.67 \\
& 67vol\% CO 2 & 0.02 & 1.50 & 882 & 0.73 \\
\hline \multirow{3}{*}{700} & 20vol\% helium & 0.07 & 3.43 & 1211 & 0.56 \\
& 50 vol\% helium & 0.12 & 3.59 & 1574 & 0.47 \\
& 80vol\% argon & 0.04 & 4.14 & 605 & 0.67 \\
& 67vol\% $\mathrm{CO}_{2}$ & 0.05 & 3.09 & 1114 & 0.71
\end{tabular}

Table 6: Gas properties of the used gas mixtures

The next step is to design the experiment. The maximum heat flux ( $\left.q_{\max }\right)$ was selected as the dependent variable for the ANOVA. All the combinations $\left(2^{2} .6=24\right)$ of the factors could be run in two test days, so it was decided to run the full factorial matrix to be able to determine second and third order interaction between the factors. Information on the random error is needed to be able to conduct a statistical test on the significance of the effect of a certain factor or interaction. This information is provided by replication of the same measurement points. Here, it was the objective to include the cyclic variation 480 in the random error. This was done using the 100 consecutive cycles that were stored for each measurement. Three different approaches were tested to find the best way to include the effect of the cyclic variation. The first approach was to divide all 100 stored cycles into two groups of 50 cycles and the maximum heat flux of the two groups was used (2 replications). However, this did not capture the cyclic variation because there was very little difference in the $q_{\max }$ of the two groups. The second approach was to use the mean plus or minus the standard deviation of the maximum heat flux of all the stored cycles ( 3 replications). This approach was abandoned as well, because the three values (mean $\pm \sigma$ ) resulted in a widening of the normal distribution of $\mathrm{q}_{\max }$ compared

490 to the actual normal distribution of the 100 cycles. The third approach was to use the maximum heat flux of randomly chosen cycles out of the 100 measured ones (2, 5 or 100 replications). This approach was chosen, as it provided the best results. Taking $\mathrm{q}_{\max }$ from all the cycles did not result in meaningful conclusions because all the effects and interactions, even the three way interaction, were

495 significant. This was caused by the fact that the degrees of freedom (df) of the error term were boosted too much, resulting in a very low mean squares value (MS) for the error term. It was concluded that a number of 5 replications was the best choice in order to have the same number of replications as the $\mathrm{df}$ of the gas factor (number of levels minus 1). The ANOVA results are presented in [1].

\subsection{Experimental design under fired conditions}

The combined effect of the gas properties and combustion was investigated under fired operation by injecting three fuels: hydrogen, methane and methanol. 
The design under fired operation has been improved compared to that under motored operation regarding the investigation of the non-linear effect of contin505 uous factors (4 out of the 5 factors), since a response surface method (RSM) has been used. Categorical factors cannot be included in the RSM design, so it has been repeated for each fuel. The RSM analysis results in an experimental surface of the dependent variable as a function of all the independent factors over their entire range. The surface of several independent variables can be 510 investigated in addition to that of the maximum heat flux: the indicated work $\left(\mathrm{W}_{\mathrm{i}}\right)$, the indicated efficiency $\left(\eta_{\mathrm{i}}\right)$ and the total cycle heat loss $\left(\mathrm{Q}_{\mathrm{h}}\right)$.

For this experiment, a central composite design (CCD) was chosen since this is the RSM design with the highest accuracy. This CCD design is visualized in Fig. 6 for an example of three factors (A, B and C). In the CCD, each factor is tested at five levels between its extreme values which are coded as -2 and 2 . The full factorial CCD (all possible combinations) consists out of three parts. The first part contains all the possible combinations of the factors at the levels -1 and 1 , which are the so called cubical points (black markers) used to test the main effects and interactions. The extreme values of a certain factor (blue markers, 520 at -2 or 2) at the centre level of the other factors (0) form the second part, which is used to test non-linear effects of that factor. The third part consists out of the replications of the centre point (red marker, all factors at level 0) to test the experimental error.

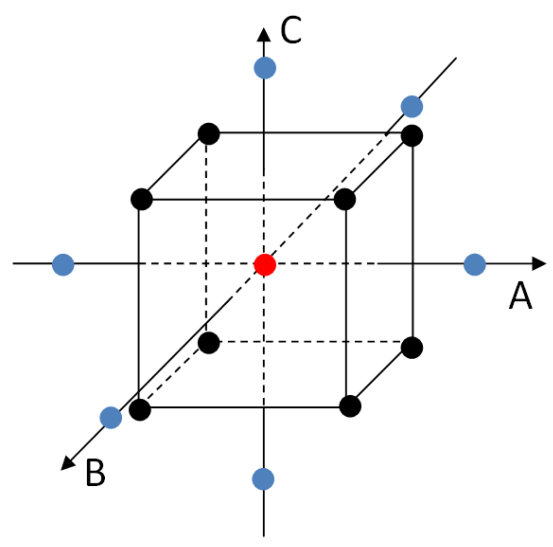

Figure 6: Central Composite Design (CCD) for three factors (A, B and C)

The extreme levels of each factor in the fired experiment are summarized in ${ }_{525}$ Table 7. The levels of IGN and $\lambda$ are fuel dependent to cover the optimal and widest possible range for each fuel. A combined wide range of IGN and $\lambda$ was not possible for hydrogen due to the occurrence of abnormal combustion with an early ignition for rich mixtures or late ignition for lean mixtures. Consequently, $\lambda$ has been varied at the lean side for hydrogen to cover the widest possible range for IGN and $\lambda$. Extra stoichiometric measurements were conducted to 
expand the data set beyond the lean mixtures.

\begin{tabular}{|c|c|c|c|}
\hline factor & fuel & level & level code \\
\hline \multirow{2}{*}{$\mathrm{TP}$} & \multirow{2}{*}{ all } & fully closed throttle (FCT) & -2 \\
\hline & & wide open throttle (WOT) & 2 \\
\hline \multirow{2}{*}{$\mathrm{CR}$} & \multirow{2}{*}{ all } & 8 & -2 \\
\hline & & 10 & 2 \\
\hline \multirow{6}{*}{ IGN } & \multirow{2}{*}{$\mathrm{CH}_{4}$} & $38^{\circ} \mathrm{ca} \mathrm{BTDC}$ & -2 \\
\hline & & $10^{\circ} \mathrm{ca} \mathrm{BTDC}$ & 2 \\
\hline & \multirow{2}{*}{$\mathrm{H}_{2}$} & $5^{\circ} \mathrm{ca} \mathrm{BTDC}$ & -2 \\
\hline & & $-15^{\circ} \mathrm{ca} \mathrm{BTDC}$ & 2 \\
\hline & \multirow{2}{*}{$\mathrm{CH}_{3} \mathrm{OH}$} & $25^{\circ} \mathrm{ca} \mathrm{BTDC}$ & -2 \\
\hline & & $5^{\circ} \mathrm{ca} \mathrm{BTDC}$ & 2 \\
\hline \multirow{6}{*}{$\lambda$} & \multirow{2}{*}{$\mathrm{CH}_{4}$} & 1.2 & -2 \\
\hline & & 0.8 & 2 \\
\hline & \multirow{2}{*}{$\mathrm{H}_{2}$} & 2.2 & -2 \\
\hline & & 1.4 & 2 \\
\hline & \multirow{2}{*}{$\mathrm{CH}_{3} \mathrm{OH}$} & 1.3 & -2 \\
\hline & & 0.7 & 2 \\
\hline
\end{tabular}

Table 7: Overview of the factors' levels under fired operation

Furthermore, in contrast to motored operation, the instant at which the heat flux peaks differs from case to case for fired operation because of the effect of the flame propagation. Therefore, the instantaneous heat flux (q) was taken as the independent variable for this experiment and the degree crank angle (ca) was added as an extra factor to investigate the time shift in the heat flux trace. This does not increase the number of runs, since the necessary combinations of the factors with the crank angle factor can be derived afterwards from the instantaneous heat flux trace. The extreme levels $(-2$ and +2$)$ are 540 chosen symmetrical around TDC and include the earliest and latest occurrence of the peak in the instantaneous heat flux. The numerical values of the crank angle factors are determined after the experiments are performed and correspond to 340 and 380 for the extreme levels. Fig. 7 shows the measured instantaneous heat flux traces for a number of measurements, together with the 5 levels of 545 the crank angle factor for the experiment. The extreme levels $(-2$ and +2$)$ are marked with two red lines and the intermediate and center levels $(-1,0$ and +1 ) with dashed black lines. It can be seen that the first two levels (2 and -1) capture the first peak of the heat flux for the measurements with an early ignition timing. Level +1 captures the second heat flux peak of the 550 measurements with an early ignition timing and the first heat flux peak of the measurements with a late ignition timing. It is to be expected that the effect of the crank angle will be captured in this way. The discussion of the measurement results is presented in part II [2]. 


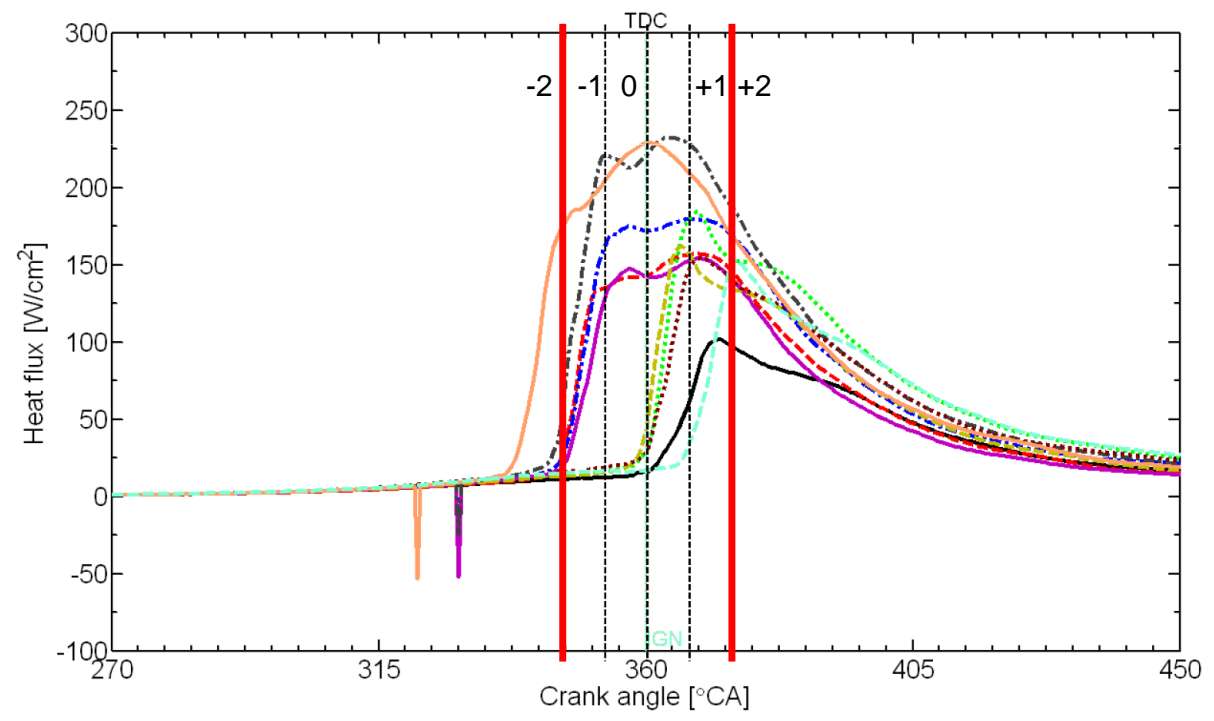

Figure 7: The instantaneous heat flux of different measurement with the five crank angle levels visualized (red line: levels -2 and +2 , black dotted line: levels $-1,0$ and +1 )

\section{Conclusion}

In this paper, a literature review was conducted of heat transfer measurements in SI engines. The measurements were divided depending on whether the engine was operated in motored or fired mode. Per operating mode the effect of the engine settings on the heat transfer was discussed. The heat transfer in an internal combustion engine under motored conditions is well understood and is mainly determined by bulk properties like the in-cylinder flow and gas temperature. Local differences in gas flow and turbulence level can cause a small spatial variation in the heat transfer around TDC and mainly during intake and exhaust stroke. The spatial variation is much more pronounced under fired conditions due to the influence of the combustion. At a certain position, the heat flux starts to rise at the instant of the flame arrival because of the sudden temperature increase. Differences in the peak heat flux are caused by local differences in gas flow, turbulence level and temperature gradient near the wall, but no firm conclusions can be made based on the reviewed data. Bulk flow properties have an effect on the heat transfer, but their effect is less pronounced than under motored conditions.

The review of the fired measurements mainly demonstrated that the investigations were approached too randomly by varying one factor at a time. The interaction between different factors cannot be investigated as a consequence. Therefore, methods of Design of Experiments need to be applied in experimental investigations to gain more insight in the heat transfer process in modern 
combustion engines. Moreover, the investigations have focused too much on the engine parameters (e.g. compression ratio, engine speed) that can be varied without linking the results with the factors that really determine the heat transfer (e.g. gas temperature, turbulence). This link is necessary for a correct modelling of the process and should be established in future investigations. For this reason a root cause analysis was executed based on the literature review to identify these independent factors. Three controllable factors were identified for motored operation: the throttle position, the compression ratio and the injected gas (type and quantity). For fired operation, the factor ignition timing was added and the factor gas was split into fuel and equivalence ratio.

Applying the Design of Experiments methodology, two kinds of experiments were designed. In the first experiment, different inert gases (helium, argon and carbon dioxide) were injected to vary the gas properties under motored operation compared to air. This allows investigating the effect of three factors: throttle position, compression ratio and gas properties on the maximum heat flux. Two levels were chosen for the first two factors and six levels were chosen for the last factor. The different inert gases were selected based on their thermal conductivity, viscosity and heat capacity that differ significantly compared to air. In the second experiment, three alternative fuels were used under fired 595 operation to investigate the additional effects during combustion. The instantaneous heat flux was chosen as the independent variable and five factors were selected: throttle position, compression ratio, ignition timing, air-to-fuel equivalence ratio and fuel. In order to investigate the non-linear effect of the factors, a response surface method with a central composite design was chosen that is repeated for each fuel. Because of the time shift in the heat flux trace, the crank angle was added as an extra factor with 5 levels. The results of the experiments are discussed in [1] for motored operation and in a companion paper 2] for fired operation.

\section{Acknowledgements}

The authors of this paper like to acknowledge the technical assistance of Koen Chielens and Patrick De Pue. The research was carried out in the framework of two Ph.D.'s funded by grants (SB-81139 and SB-141289) of the Institute for the Promotion of Innovation through Science and Technology in Flanders (IWT-Vlaanderen). The experimental equipment is funded by a Research Grant ${ }_{610}(1.5 .147 .10 \mathrm{~N})$ of the Research Foundation - Flanders (FWO). The financial support is gratefully acknowledged. 


\section{Abbreviations and definitions}

$\begin{array}{ll}\text { Abbreviations } \\ \text { ABDC } & \text { after bottom dead center } \\ \text { AFR } & \text { air-to-fuel ratio } \\ \text { ANOVA } & \text { analysis of variance } \\ \text { ATDC } & \text { after top dead center } \\ \text { BBDC } & \text { before bottom dead center } \\ \text { CCD } & \text { central composite design } \\ \text { CFR } & \text { Cooperative Fuel Research } \\ \text { CR } & \text { compression ratio } \\ \text { df } & \text { degrees of freedom } \\ \text { EV } & \text { exhaust valve } \\ \text { EVO } & \text { exhaust valve opening time } \\ \text { FCT } & \text { fully closed throttle } \\ \text { HCCI } & \text { homogeneous charge compression ignition } \\ \text { IGN } & \text { ignition timing } \\ \text { IV } & \text { intake valve } \\ \text { IVO } & \text { intake valve opening time } \\ \text { MBT } & \text { minimum spark advance for maximum brake torque } \\ \text { MS } & \text { mean squares } \\ \text { RSM } & \text { response surface method } \\ \text { RTD } & \text { resistance temperature detector } \\ \text { SI } & \text { spark ignition } \\ \text { SP } & \text { spark plug } \\ \text { TDC } & \text { top dead center } \\ \text { TP } & \text { throttle position } \\ \text { WOT } & \text { wide open throttle }\end{array}$




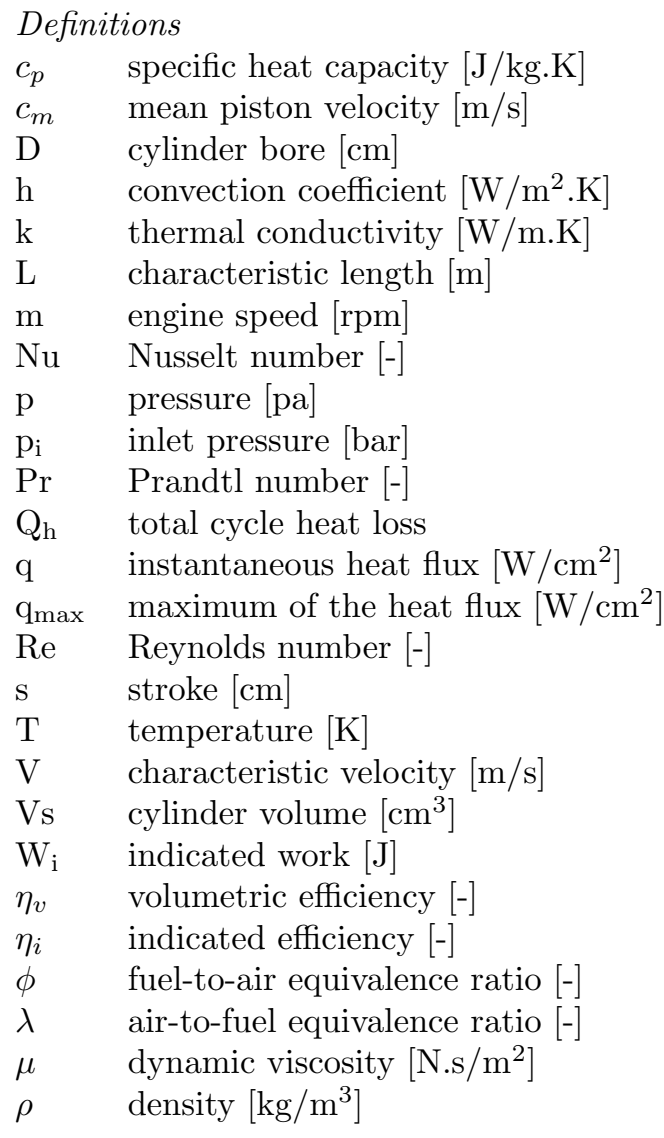

\section{References}

[1] J. Demuynck, M. De Paepe, L. Sileghem, J. Vancoillie, S. Verhelst, K. Chana, Applying design of experiments to determine the effect of gas properties on in-cylinder heat flux in a motored SI engine, SAE Int. J. Engines 5 (3).

[2] T. De Cuyper, J. Demuynck, S. Broekaert, S. Verhelst, M. De Paepe, Heat transfer in premixed spark ignition engines part II: Systematic analysis of the heat transfer phenomena, Submitted to Energy.

[3] K. Elser, Instationäre wärmeübertragung bei periodisch adiabater verdichtung turbulenter gase, Forschung auf dem Gebiete des Ingenieurwesens 21 (3) (1955) 65-74.

[4] M. Yamakawa, T. Youso, T. Fujikawa, T. Nishimoto, Y. Wada, K. Sato, H. Yokohata, Combustion technology development for a high compression ratio SI engine, SAE paper 2011-01-1871 (2011). 
[5] B. Deng, J. Fu, D. Zhang, J. Yang, R. Feng, J. Liu, K. Li, X. Liu, The heat release analysis of bio-butanol/gasoline blends on a high speed SI (spark ignition) engine, Energy 60 (2013) 230-241.

[6] G. Kosmadakis, E. Pariotis, C. Rakopoulos, Heat transfer and crevice flow in a hydrogen-fueled spark-ignition engine: Effect on the engine performance and NO exhaust emissions, international journal of hydrogen energy 38 (2013) 7477-7489.

[7] G. Borman, K. Nishiwaki, Internal-combustion engine heat-transfer, Progress in Energy and Combustion Science 13 (1) (1987) 1-46.

[8] J. Welty, C. Wicks, R. Wilson, G. Rorrer, Fundamentals of Momentum, Heat and Mass transfer, 4th Edition, John Wiley and Sons, New York, 2001.

[9] W. Annand, Heat transfer in the cylinders of reciprocating internal combustion engines, Proc Instn Mech Engrs 177 (36) (1963) 973-996.

[10] G. Woschni, A universally applicable equation for the instantaneous heat transfer coefficient in the internal combustion engine, SAE paper 670931 (1967).

[11] G. Woschni, Beitrag zum problem des wärmeüberganges im verbrenningsmotor, Motortechnische Zeitschrift 26 (4) (1965) 128-133.

[12] T. Shudo, H. Suzuki, Applicability of heat transfer equations to hydrogen combustion, Jsae Review 23 (3) (2002) 303-308.

[13] J. Demuynck, M. De Paepe, H. Huisseune, R. Sierens, J. Vancoillie, S. Verhelst, On the applicability of empirical heat transfer models for hydrogen combustion engines, International Journal of Hydrogen Energy 36 (1) (2011) 975-984.

[14] J. Chang, O. Guralp, Z. Filipi, D. Assanis, New heat transfer correlation for an HCCI engine derived from measurements of instantaneous surface heat flux, SAE paper 2004-01-2996 (2004).

[15] H. Soyhan, H. Yasar, H. Walmsley, B. Head, G. Kalghatgi, C. Sorusbay, Evaluation of heat transfer correlations for HCCI engine modeling, Applied Thermal Engineering 29 (2-3) (2009) 541-549.

[16] S. Broekaert, T. De Cuyper, K. Chana, M. De Paepe, S. Verhelst, Assessment of empirical heat transfer models for a CFR engine operated in HCCI mode, SAE paper 2015-01-1750 (2015).

[17] P. Berger, Experimental Design with Applications in Management, Engineering, and the Sciences, Duxbury, Belmont, USA, 2002.

[18] D. Boggs, Spatially-resolved measurements of instantaneous engine heat flux, Ph.D. thesis, University of Wisconsin-Madison (1990). 
[19] D. Boggs, G. Borman, Calculation of heat flux integral length scales from spatially-resolved surface temperature measurements in an engine, SAE paper 910721 (1991).

[20] V. Overbye, J. Bennethum, O. Uyehara, P. Myers, Unsteady heat transfer in engines, SAE paper 610041 (1961).

[21] H. Hassan, Unsteady heat transfer in a motored I.C. engine cylinder, Proc Instn Mech Engrs 185 (80) (1971) 1139-1148.

[22] J. Dent, S. Suliaman, Convective and radiative heat transfer in a high swirl direct injection diesel engine, SAE paper 770407 (1977).

[23] K. Dao, O. Uyehara, P. Myers, Heat transfer rates at gas-wall interfaces in motored piston engine, SAE paper 730632 (1973).

[24] A. Alkidas, Heat transfer characteristics of a spark-ignition engine, Journal of Heat Transfer - Transactions of the ASME 102 (2) (1980) 189-193.

[25] B. Lawton, Effect of compression and expansion on instantaneous heat transfer in reciprocating internal combustion engines, Proceedings of the Institution of Mechanical Engineers Part A - Journal of Power and Energy 201 (3) (1987) 175-186.

[26] R. Lucht, D. Dunn-Rankin, T. Walter, T. Dreier, S. Bopp, Heat transfer in engines: Comparison of CARS thermal boundary layer measurements and heat flux measurements, SAE paper 910722 (1991).

[27] D. Nijeweme, J. Kok, C. Stone, L. Wyszynski, Unsteady in-cylinder heat transfer in a spark ignition engine: experiments and modelling, Proceedings of the Institution of Mechanical Engineers Part D - Journal of Automobile Engineering 215 (D6) (2001) 747-760.

[28] A. Burluka, A. El-Dein Hussin, Z. Ling, C. Sheppard, Effects of largescale turbulence on cyclic variability in spark-ignition engine, Experimental Thermal and Fluid Science 43 (2012) 13-22.

[29] B. Tillock, J. Martin, Measurement and modeling of thermal flows in an air-cooled engine, SAE paper 961731 (1996).

[30] A. Alkidas, J. Myers, Transient heat-flux measurements in the combustionchamber of a spark-ignition engine, Journal of Heat Transfer-Transactions of the ASME 104 (1) (1982) 62-67.

[31] A. Alkidas, I.-S. Suh, The effects on intake flow configuration on the heat release and heat transfer characteristics of a single-cylinder four-valve SI engine, SAE paper 910296 (1991). 
[32] Y. Enomoto, S. Furuhama, Study on thin film thermocouple for measuring instantaneous temperature on surface of combustion chamber wall in internal combustion engine, Bulletin of the JSME-Japan Society of Mechanical Engineers 28 (235) (1985) 108-116.

[33] Y. Enomoto, S. Furuhama, K. Minakami, Heat loss to combustion chamber wall of 4-stroke gasoline engine, Bulletin of the JSME-Japan Society of Mechanical Engineers 28 (238) (1985) 647-655.

[34] Y. Enomoto, S. Furuhama, Heat loss into combustion chamber wall of 4stroke gasoline engine, Bulletin of the JSME-Japan Society of Mechanical Engineers 29 (253) (1986) 2196-2203.

[35] Y. Enomoto, S. Furuhama, Heat transfer to wall of ceramic combustion chamber of internal combustion engine, Bulletin of the JSME-Japan Society of Mechanical Engineers 29 (250) (1986) 1211-1217.

[36] Y. Enomoto, S. Furuhama, Study on thin film thermocouple measuring instantaneous temperatures on surface of combustion chamber wall in internal combustion engine, Bulletin of the JSME-Japan Society of Mechanical Engineers 29 (256) (1986) 3434-3441.

[37] T. Shudo, Y. Nakajima, T. Futakuchi, Thermal efficiency analysis in a hydrogen premixed combustion engine, JSAE Review 21 (2) (2000) 177182.

[38] P. Gilaber, P. Pinchon, Measurements and multidimensional modeling of gas-wall heat transfer in a S.I. engine, SAE paper 880516 (1988).

[39] G. Choi, K. Choi, J. Lee, Y. Song, Y. Ryu, J. Cho, Analysis of combustion chamber temperature and heat flux in a DOHC engine, SAE paper 970895 (1997).

[40] J.-L. Saulnier, A. Dupont, J.-P. Rivere, J. Jullien, Effects of aerodynamics on fuel consumption of a multivalve SI engine. investigation of the instantaneous local heat transfer at part loads and distinct equivalence ratios, SAE paper 972938 (1997).

[41] X. Wang, P. Price, C. Stone, D. Richardson, Heat release and heat flux in a spray-guided direct-injection gasoline engine, Proceedings of the Institution of Mechanical Engineers Part D-Journal of Automobile Engineering 221 (D11) (2007) 1441-1452.

[42] J. Michl, M. Schenk, H. Rottengruber, W. Huhn, Thermal boundary conditions in a stoichiometric operating hydrogen engine, F2008-06-110 (2008).

[43] J. Heywood, Internal Combustion Engine Fundamentals, McGraw-Hill, 1988. 
[44] R. Rowley, W. Wilding, J. Oscarson, Y. Yang, N. Zundel, T. Daubert, R. Danner, DIPPR Data Compilation of Pure Compound Properties, Design Institute for Physical Properties, AIChE, New York (NY), 2003.

740 [45] R. Reid, J. Prausnitz, B. Poling, The properties of Gases and Liquids, McGraw-Hill Book Co., Singapore, 1988. 